\title{
Synergistic approach to polycycles through Suzuki-Miyaura cross coupling and metathesis as key steps
}

\author{
Sambasivarao Kotha*, Milind Meshram and Chandravathi Chakkapalli
}

\author{
Review \\ Address: \\ Department of Chemistry, Indian Institute of Technology Bombay, \\ Powai, Mumbai-400 076, India, Fax: +91(22)-2576 7152 \\ Email: \\ Sambasivarao Kotha* - srk@chem.iitb.ac.in \\ * Corresponding author \\ Keywords: \\ Claisen rearrangement; Diels-Alder reaction; metathesis; polycycles; \\ Suzuki-Miyaura cross coupling
}

\author{
Beilstein J. Org. Chem. 2018, 14, 2468-2481. \\ doi:10.3762/bjoc. 14.223
}

Received: 29 May 2018

Accepted: 28 August 2018

Published: 21 September 2018

This article is part of the thematic issue "Progress in metathesis chemistry III".

Guest Editor: K. Grela

(C) 2018 Kotha et al.; licensee Beilstein-Institut.

License and terms: see end of document.

\begin{abstract}
This account provides an overview of recent work, including our own contribution dealing with Suzuki-Miyaura cross coupling in combination with metathesis (or vice-versa). Several cyclophanes, polycycles, macrocycles, spirocycles, stilbenes, biaryls, and heterocycles have been synthesized by employing a combination of Suzuki cross-coupling and metathesis. Various popular reactions such as Diels-Alder reaction, Claisen rearrangement, cross-metathesis, and cross-enyne metathesis are used. The synergistic combination of these powerful reactions is found to be useful for the construction of complex targets and fulfill synthetic brevity.
\end{abstract}

\section{Introduction}

Transition-metal catalysts are used in metathesis and cross-coupling reactions. Such advances have opened the door for efficient construction of $\mathrm{C}-\mathrm{C}$ bonds in organic synthesis. These catalysts tolerate diverse functional groups and the reaction occurs under mild reaction conditions. Among different metathetic processes, ring-closing metathesis (RCM) [1-6] is of a greater interest than cross-metathesis (CM). It is a widely used protocol for the synthesis of unsaturated cyclic systems [7]. Palladium-catalyzed Suzuki-Miyaura (SM) cross-coupling reaction is also considered as one of the most versatile methods for $\mathrm{C}-\mathrm{C}$ bond formation [8-12]. Application of a wide range of organometallic reagents (e.g., organoboron reagents) are possible due to their commercial availability. Owing to the mild reaction conditions and ease of handling of organoboron reagents [13-17] have propelled the growth of the SM cross coupling. A synergistic combination of these two elegant methods (i.e., SM coupling and metathesis) [18] was found to increase the synthetic efficiency of complex targets (e.g., macrocycles [19-22], oligomers [23,24], polycyclic ethers [25], heterocycles [26], nonbenzenoid aromatics [27], and spirocycles $[28,29])$ by decreasing the number of steps. Different metathesis catalysts used in this study are shown in Figure 1. 
<smiles></smiles>

Grubbs 1st generation catalyst (G-I) 1

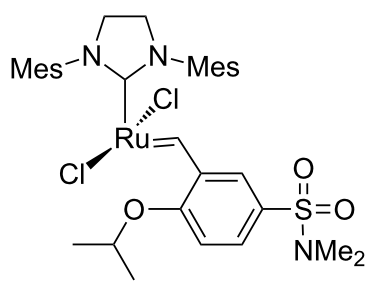

Zhan-1B (4)<smiles></smiles>

Grubbs 2nd generation catalyst (G-II) 2

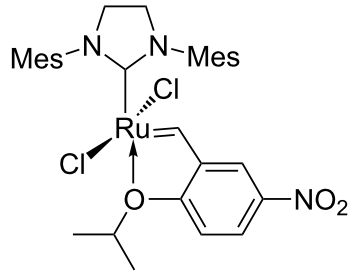

[Ru-2] 5

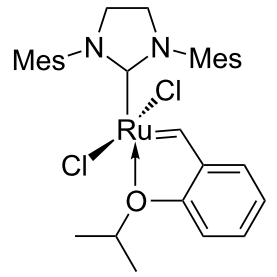

Hoveyda-Grubbs

2nd generation catalyst (HG-II) 3

Figure 1: Various catalysts used for metathesis reactions

\section{Review}

\section{Annulation}

Grela and co-workers [30] demonstrated a useful protocol to build indene derivatives by employing SM coupling and RCM in sequence. To this end, the SM coupling of triflate 7 was accomplished by using pinacol boronic ester $\mathbf{8}$ in the presence of a palladium catalyst to give the cross-coupling product 9 (75\%). Later on, exposure of the diolefinic precursor 9 to [Ru-2] catalyst 5 gave the ring-closure product $\mathbf{1 0}$ in quantitative yield (Scheme 1).

A sequential usage of SM cross coupling and RCM was responsible to construct various naphthalene derivatives such as $\mathbf{1 5}$ [31]. The SM coupling product 3,4-diallylbenzene derivative 13 (90\%) was obtained from diiodobenzene 11 using allylboronate ester 12 via a SM-type allylation sequence [32]. Next, compound $\mathbf{1 3}$ was exposed to Grubbs 1st generation (G-I) catalyst $\mathbf{1}$ to effect the ring-closure to produce tetrahydronaphthalene derivative 14 (92\%). Subsequently, aromatization of compound 14 was accomplished with 2,3-dichloro-5,6-dicyano-1,4-benzoquinone (DDQ) to generate nitronaphthalene $15(60 \%$, Scheme 2).

Due to their useful biological activity and intricate structural features of angucyclines such as 16-19 (Figure 2), several approaches have been reported for their assembly. In this context, de Koning and co-workers [33] demonstrated an efficient route for the construction of the benz $[a]$ anthracene structural unit by employing SM cross coupling followed by RCM sequence. Treatment of the bromonaphthalene derivative $\mathbf{2 0}$ with<smiles>[3H]C(=O)OC(=C)CCC(=O)OB1OC(C)(C)C(C)(C)O1</smiles><smiles>C=CCc1cc([N+](=O)[O-])ccc1C(=C)CCC(=O)OCC</smiles>

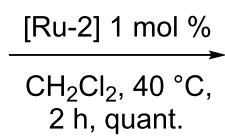<smiles>CCOC(=O)CCC1=CCc2cc([N+](=O)[O-])ccc21</smiles>

8 


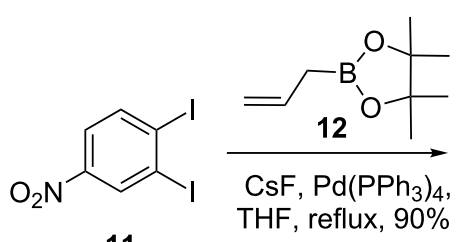

11

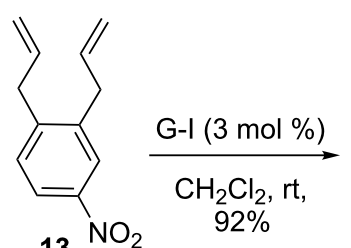

$13 \mathrm{NO}_{2}$

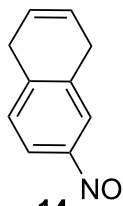

${ }_{14} \mathrm{NO}_{2}$

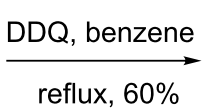

reflux, $60 \%$

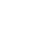<smiles>COc1cccc2c1C(=O)c1ccc3c(c1C2=O)C(=O)CC(C)C3</smiles>

(+)-rubiginone B2 (16)<smiles>CC1CC(=O)c2c(ccc3c2C(=O)c2cccc(O)c2C3=O)C1</smiles>

(+)-ochromycinone (17)<smiles>CC1(O)CC(=O)c2c(ccc3c2C(=O)c2cccc(O)c2C3=O)C1</smiles>

tetrangomycin (18)<smiles>Cc1cc(O)c2c3c(ccc2c1)C(=O)c1cccc(O)c1C3=O</smiles>

tetrangulol (19)

Figure 2: Various angucyclines.

(2-formyl-4-methoxyphenyl)boronic acid (21) in the presence of a palladium catalyst generated the cross-coupling product $\mathbf{2 2}$ (72\%). Next, aldehyde 22 was subjected to Wittig olefination to provide the corresponding alkene 23 (69\%), which on subsequent treatment with $\mathrm{KO} t$-Bu in THF gave the isomerized product 24 (73\%). Later, RCM of isomerized olefin 24 with the help of G-II catalyst offered the ring-closure product 25 (84\%). Finally, CAN oxidation gave the desired tetracyclic compound 26 in 84\% yield (Scheme 3).

\section{Spirocycles}

In another event, an efficient approach to spirocyclopentane derivatives has been described, where the combination of RCM and SM coupling was employed [34]. In this respect, the key building block 29 was derived by employing a sequential $O$-allylation and $\mathrm{CR}$, then again $O$-allylation, and CR [35] starting with a commercially available 6-bromo-2-naphthol (27). Subsequently, the diallyl derivative 29 was exposed to G-II catalyst 2 to deliver a ring-closure product $\mathbf{3 0}(83 \%)$. Finally, the spiro compound $\mathbf{3 0}$ was subjected to the SM coupling using two different boronic acids to produce the aryl substituted spiro compounds such as 31 (96\%) and 32 (79\%) (Scheme 4).

Along similar lines, we have also demonstrated the synthesis of bis-spirocycles such as $\mathbf{3 7}$ by adopting a double RCM sequence followed by SM coupling [36]. The key precursor 34 was assembled from a commercially available tetralone $\mathbf{3 3}$ via

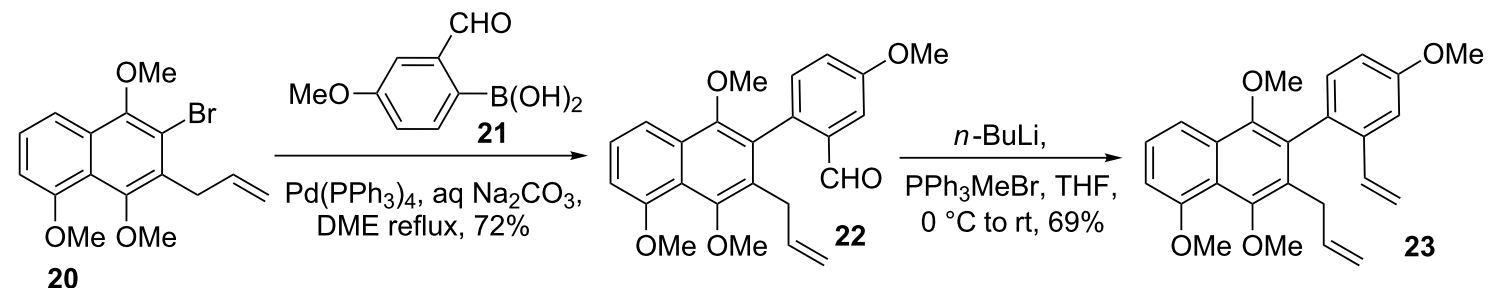

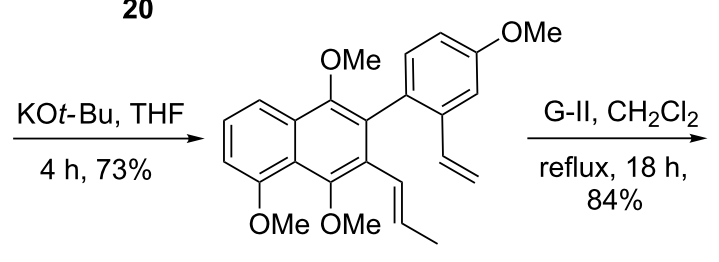

24<smiles>COc1ccc2c(ccc3c(OC)c4c(OC)cccc4c(OC)c32)c1</smiles>

25<smiles>COc1ccc2c3c(ccc2c1)C(=O)c1c(OC)cccc1C3=O</smiles>

26 


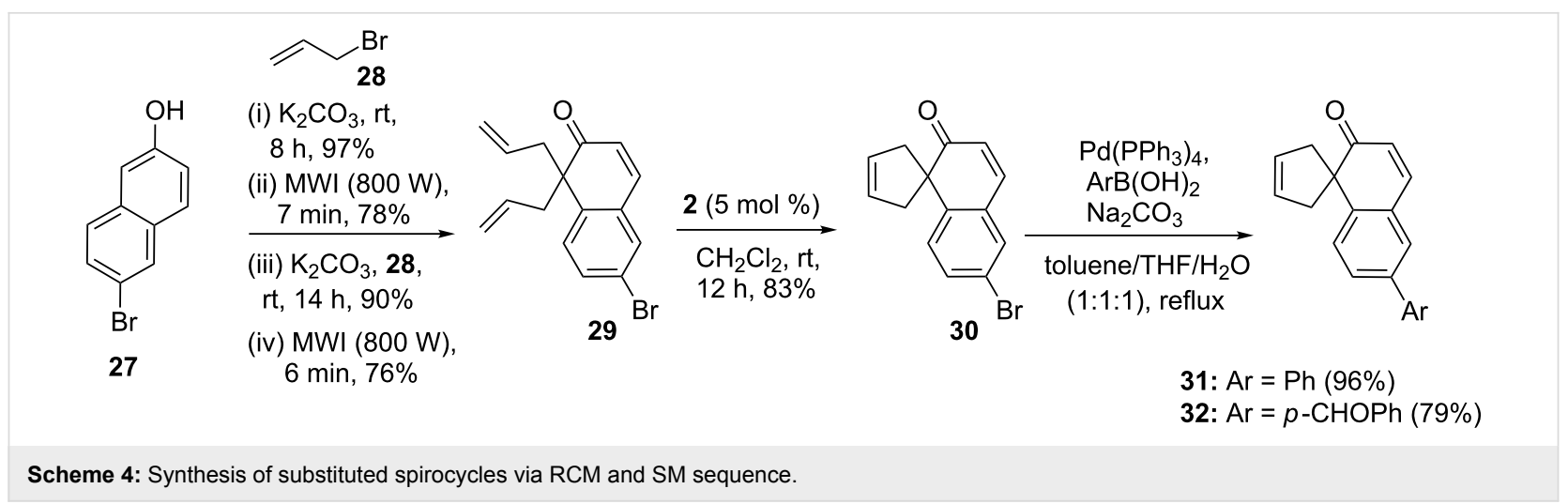

tetraallylation sequence. Then, tetraallyl derivative $\mathbf{3 4}$ was subjected to RCM with the aid of the G-I catalyst $\mathbf{1}$ to furnish the bis-spirocyclic compound $\mathbf{3 5}(90 \%)$. Next, the cyclized product 35 was subjected to SM coupling using phenylboronic acid (36) to afford the cross-coupling product 37 (97\%, Scheme 5).

In another instance, a simple synthetic approach to spiro-fluorene derivative $\mathbf{4 1}$ was described involving a serial usage of RCM and SM coupling [37]. To this end, bromofluorene $\mathbf{3 8}$ was reacted with allyl bromide (28) in the presence of $50 \% \mathrm{NaOH}$ to deliver the expected 9,9'-diallylfluorene derivative 39 (90\%). Next, diallyl compound 39 was subjected to RCM with the aid of the G-I catalyst $\mathbf{1}$ to furnish a ring-closure product, spirofluorene derivative 40 (93\%). Later, the dibromide 40 was subjected to SM coupling in the presence of phenylboronic acid (36) to generate the new spirofluorene 41 (88\%, Scheme 6).
Interestingly, highly substituted truxene derivatives $\mathbf{4 5 - 4 9}$ were also synthesized by applying the RCM and SM coupling protocol (Scheme 7).

\section{Heterocycles}

Couture and co-workers [38] demonstrated an elegant approach to highly substituted isoquinolones (e.g., 57a-d, Scheme 8) by employing a SM coupling followed by RCM. To this end, they started with $o$-vinylbenzoic acid and it was transformed to the benzamide derivatives $\mathbf{5 0}$ by employing a four-step synthetic sequence. Later, compound $\mathbf{5 0}$ was treated with KHMDS in THF at $-78{ }^{\circ} \mathrm{C}$ to produce enolate 51. Further, it was reacted with diphenyl chlorophosphate to generate vinyl phosphate 52, which was subjected to SM coupling in the presence of different 2-formylboronic acids 53 with the aid of the $\mathrm{Pd}\left(\mathrm{PPh}_{3}\right)_{4}$ catalyst to provide the respective coupling products $\mathbf{5 4 a - d}$

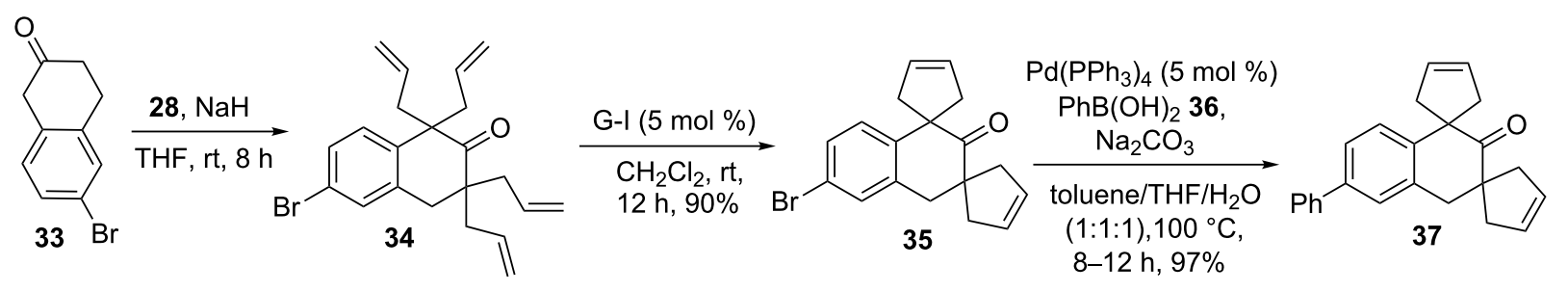

Scheme 5: Synthesis of highly functionalized bis-spirocyclic derivative 37 .

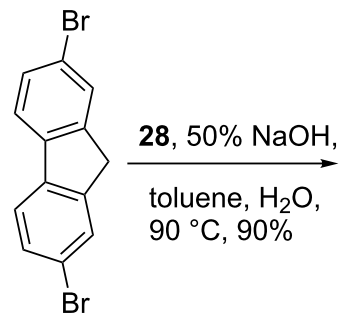

38<smiles>C=CCC1(CC=C)c2cc(Br)ccc2-c2ccc(Br)cc21</smiles>

39

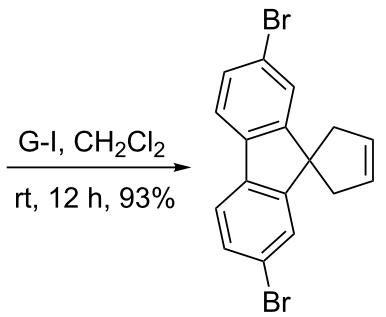

40
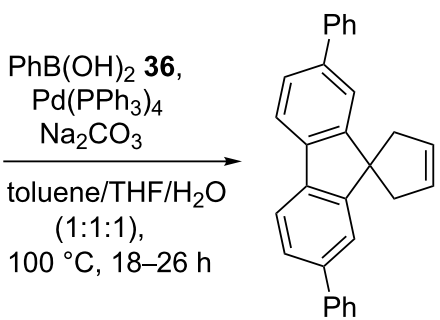

$41(88 \%)$

Scheme 6: Synthesis of spirofluorene derivatives via RCM and SM coupling sequence. 
<smiles>c1ccc2c(c1)Cc1c3c(c4c(c1-2)Cc1ccccc1-4)-c1ccccc1C3</smiles>

(i) $\mathrm{Br}_{2}, \mathrm{CH}_{2} \mathrm{Cl}_{2}$, rt $15 \mathrm{~h}, 97 \%$

(ii) $t$-BuOK, THF, allyl bromide (28), reflux, $24 \mathrm{~h}, 69 \%$
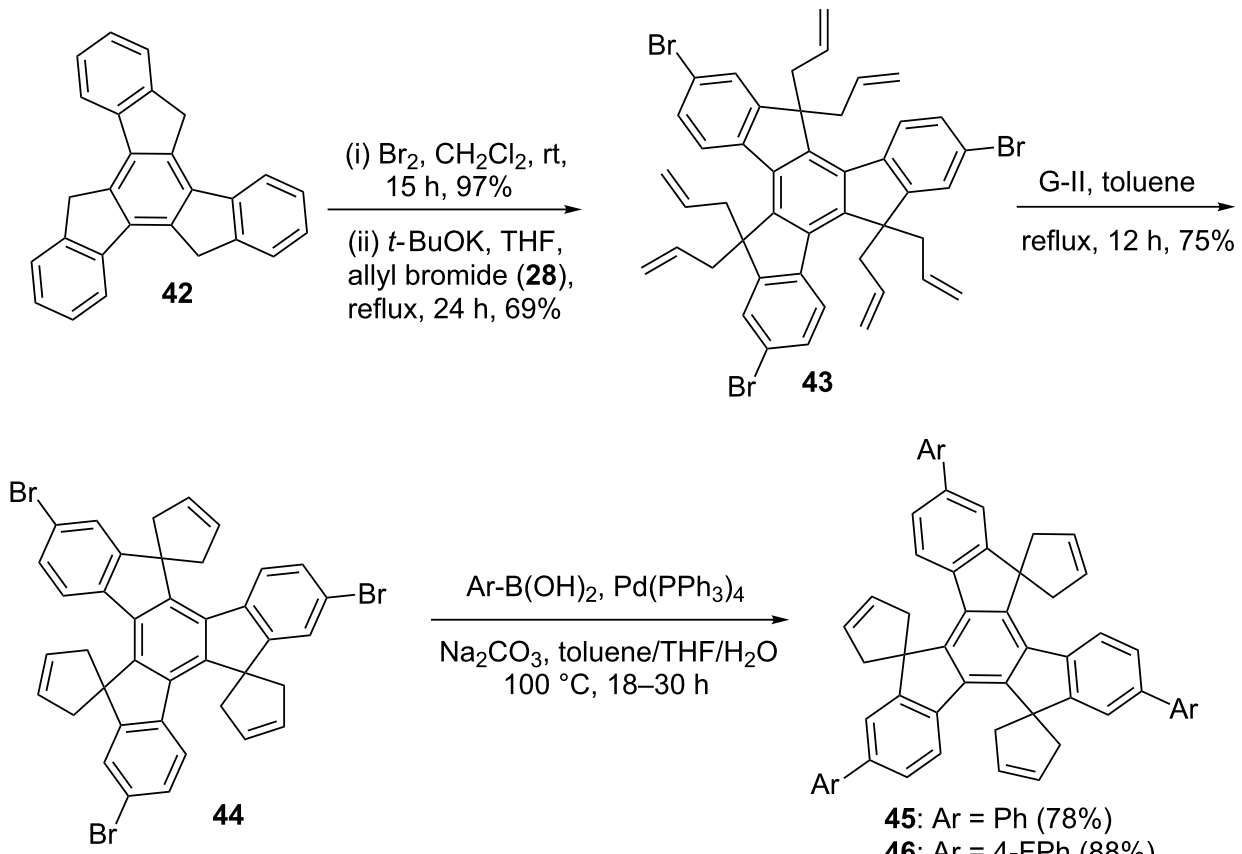

45: $\mathrm{Ar}=\mathrm{Ph}(78 \%)$

46: $\mathrm{Ar}=4-\mathrm{FPh}(88 \%)$

47: $\mathrm{Ar}=4-\mathrm{CF}_{3} \mathrm{Ph}(74 \%)$

48: $\mathrm{Ar}=4-\mathrm{COCH}_{3} \mathrm{Ph}(68 \%)$

49: $\mathrm{Ar}=4-\mathrm{CHOPh}(69 \%)$

Scheme 7: Synthesis of truxene derivatives via RCM and SM coupling<smiles>[R]c1cc([B]O)c(C=O)cc1[R9]</smiles>

53

$\mathrm{THF} / \mathrm{H}_{2} \mathrm{O}$, reflux

2 h, $72-87 \%$

$10 \% \mathrm{HCl}$ in acetone

rt, $24 \mathrm{~h}, 81-93 \%$<smiles>[R]c1cc([R1])c(C(=O)N([R1])C(=O)OCC)c(C=C)c1</smiles><smiles>[R6]c1cc(C=C)c(C(=O)N([R])C(=C)OP(=O)(O)OP(=O)(O)c2ccccc2)cc1[R]</smiles>

52<smiles>[R8]c1cc(C=O)c(-c2cc3cc([R])c([R])cc3c(=O)n2[R])cc1[R]</smiles>

55a-d 54a: $R^{1}=R^{2}=H ; R^{3}=M e ; R^{4}=R^{5}=H$

54b: $R^{1}=R^{2}=H ; R^{3}=M e ; R^{4}=O M e ; R^{5}=H$

54c: $R^{1}=R^{2}=$ OMe; $R^{3}=M e ; R^{4}=R^{5}=H$

54d: $R^{1}=R^{2}=H ; R^{3}=B n ; R^{4}=H ; R^{5}=O M e$

Scheme 8: Synthesis of substituted isoquinoline derivative via SM and RCM protocol. 
(72-87\%). Next, exposure of the diolefins $54 a-d$ to G-II catalyst 2 delivered ring-closure products, iso-quinolones $\mathbf{5 5 a - d}$ (76-88\%). Finally, the cyclized products 55a-d were converted into the corresponding indeno[1,2-c]isoquinolin-5,11-diones 57a-d (73-85\%) through cyclization with the aid of $\mathrm{HCl}$ followed by pyridinium dichromate (PDC) oxidation (Scheme 8 ).

Schmidt and co-workers [39] described an efficient route involving RCM and SM coupling towards the synthesis of 8-arylsubstituted coumarin 64, a natural product isolated from the plant Galipea panamensis. To this end, aldehydes 58a,b were subjected to a Wittig olefination followed by condensation with acryloyl chloride $(\mathbf{6 0})$ to generate the corresponding diolefinic substrates such as $61 \mathbf{a}(70 \%)$ and $\mathbf{6 1 b}(65 \%)$. Later, these diolefins $61 \mathbf{a}, \mathbf{b}$ were subjected to RCM with the aid of G-II catalyst 2 to furnish the respective ring-closure products 62a (98\%) and 62b (97\%). Finally, SM coupling of 8-halo-7methoxycoumarins 62a,b with (4-methylfuran-3-yl)boronic acid (63) delivered the cross-coupling product 64 (Scheme 9).

In another event, Magnier and co-workers [40] described a simple synthetic route to sulfoximines by adopting SM coupling and RCM as key steps. In this respect, SM coupling of sulfoximine $\mathbf{6 5}$ with potassium vinyltrifluoroborate $(\mathbf{6 6})$ in the presence of a palladium catalyst produced vinyl sulfoximine derivative 67 (73\%). Next, $N$-alkenylation of sulfoximine 67 was accomplished with $Z$-vinyl bromide (68) to generate diolefinic substrate $69(86 \%)$. Finally, diolefin 69 was exposed to Hoveyda-Grubbs 2nd generation catalyst (HG-II) 3 to deliver the cyclic sulfoximine $\mathbf{7 0}$ in $98 \%$ yield (Scheme 10).

Additionally, we also demonstrated a sequential usage of SM coupling and the RCM protocol to construct 1-benzazepine derivative 75 [41]. To this end, iodoacetanilide 71 was subjected to SM coupling in the presence of allyboronate ester $\mathbf{1 2}$ to give ortho-allylacetanilide (72), which was further modified by $\mathrm{N}$-allylation with allyl bromide (28) to offer a mixture of diallyl compound 73a (82\%) and isomerized product $\mathbf{7 3 b}(8 \%)$. Next, exposure of the diallyl derivative 73a to G-II catalyst 2 yielded the cyclized product 74 (72\%). Eventually, hydrogenation of the RCM product 74 was achieved with $\mathrm{H}_{2}, \mathrm{Pd} / \mathrm{C}$ conditions to give the saturated 2,3,4,5-tetrahydro-1-benzazepine $\mathbf{7 5}$ in $81 \%$ yield (Scheme 11).

Naphthoxepine derivatives play an important role as cosmetics and as pharmaceutical ingredients. Therefore, we conceived a simple approach, where the SM coupling and RCM were employed as critical steps $[42,43]$. Our journey begin with $O$-ally-

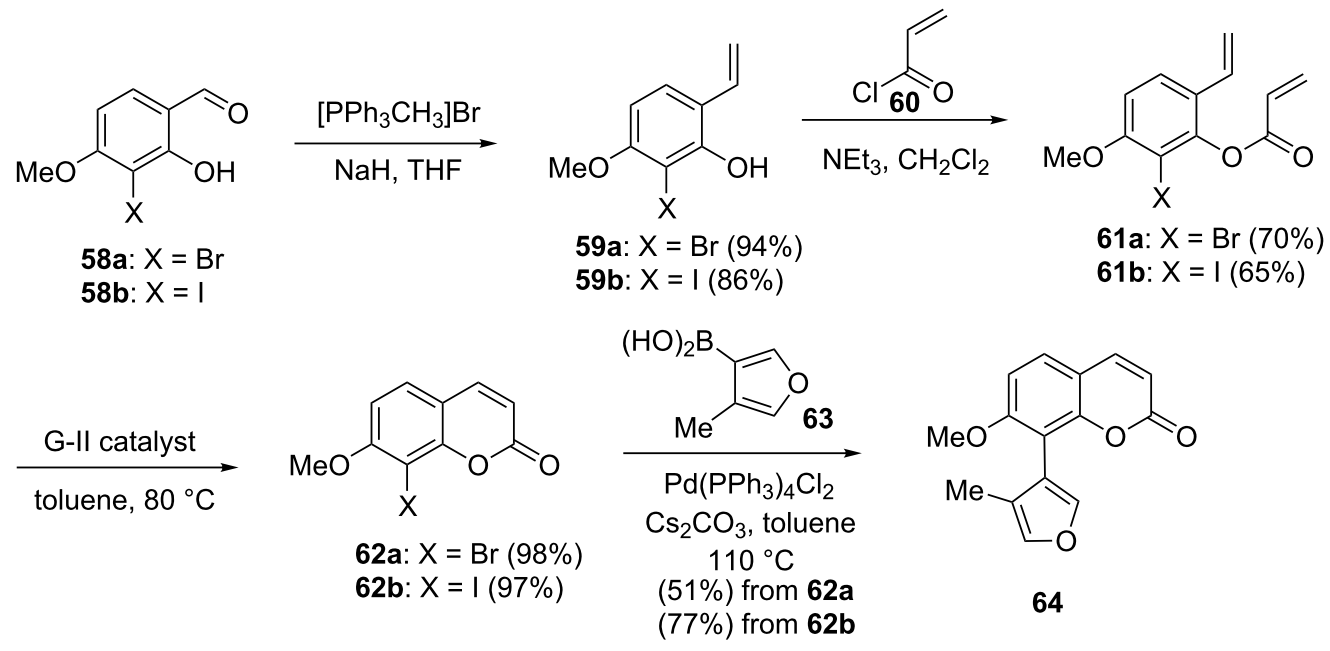

Scheme 9: Synthesis to 8-aryl substituted coumarin 64 via RCM and SM sequence.

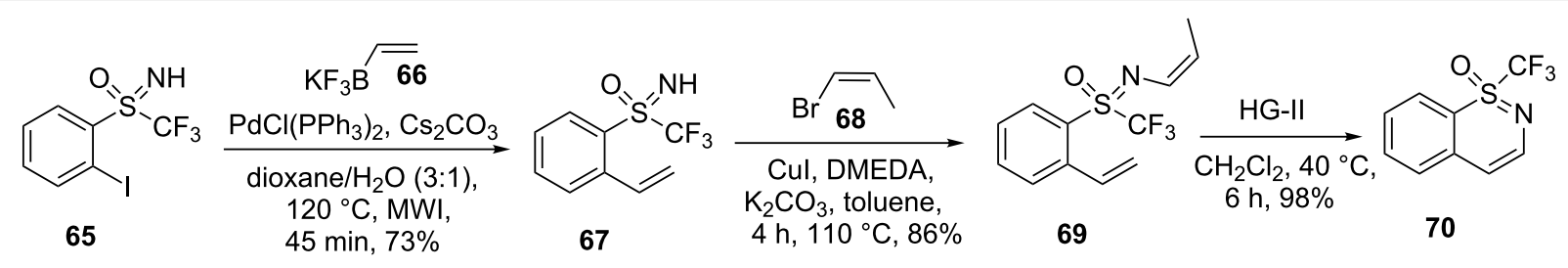

Scheme 10: Synthesis of cyclic sulfoximine 70 via SM and RCM as key steps. 


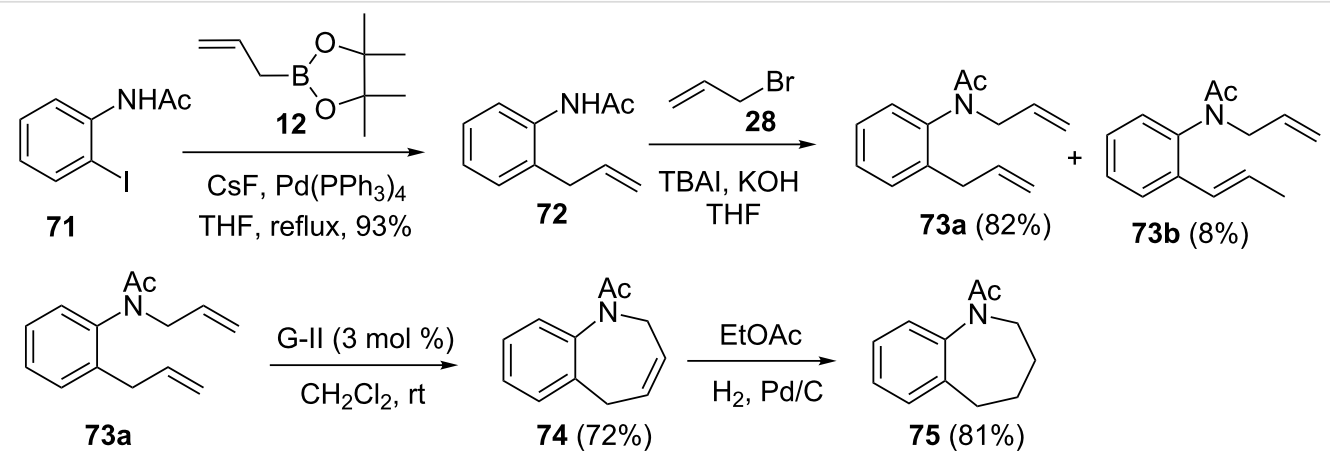

Scheme 11: Synthesis of 1-benzazepine derivative 75 via SM and RCM as key steps.

lation of $\beta$-naphthol $\mathbf{7 6}$ by using allyl bromide (28) to give $O$-allyl derivative $\mathbf{7 7}$. Then, Claisen rearrangement (CR) of 77 under microwave irradiation (MWI) conditions on a silica gel support followed by $O$-allylation of the resulting $\mathrm{CR}$ product furnished diallyl compound 78. Treatment of diallyl compound $\mathbf{7 8}$ with G-I catalyst $\mathbf{1}$ delivered the expected naphthoxepine derivative 79 (96\%). Next, Suzuki coupling of 79 with diverse arylboronic acids (e.g., phenylboronic acid (36)) gave a highly substituted naphthoxepine derivative 80 (90\%) (Scheme 12).

\section{Stilbene derivatives}

Hoveyda and co-workers [44] reported the synthesis of $Z$-(pinacolato)allylboron and $Z$-(pinacolato)alkenylboron derivatives via $\mathrm{CM}$ by using Mo complex 6. In this regard, they assembled stilbene derivative $\mathbf{8 5}$ as an antitumor agent by a two-step strategy that involve catalytic CM and SM coupling. To this end, the $Z$-selective $C M$ of a styrene derivative (e.g., 81) with vinyl-B(pin) 82 was realized in the presence of Mo complex 6 to provide a highly substituted vinyl-B(pin) 83 (73\%) with
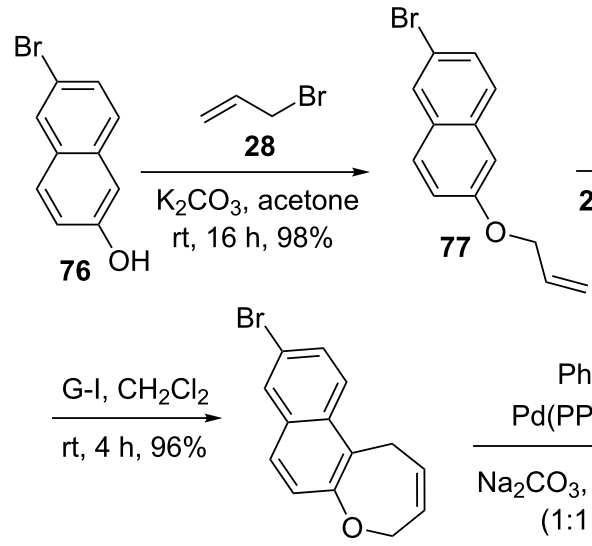

79

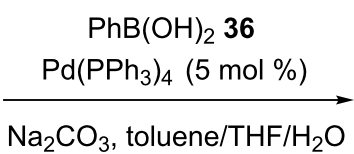

$(1: 1: 1)$, reflux, $90 \%$
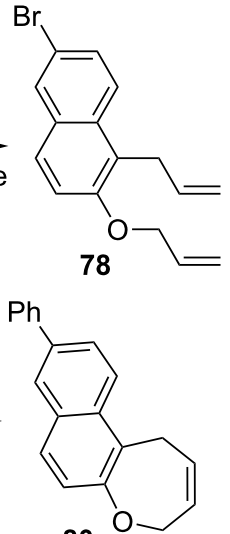

Scheme 12: Synthesis of naphthoxepine derivative 79 via RCM followed by SM coupling.

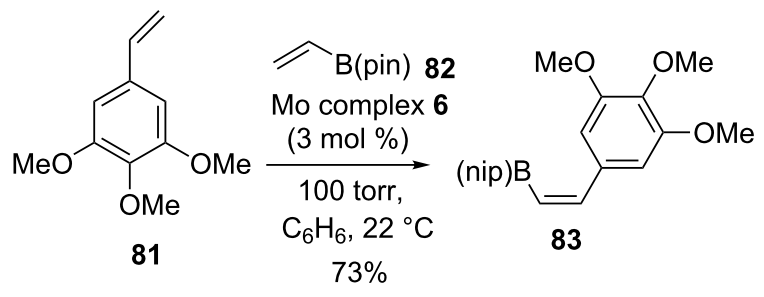

$73 \%$

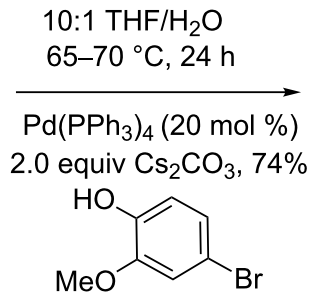

84 
excellent selectivity (96:4 Z:E). Further, vinylboron compound $\mathbf{8 3}$ was subjected to SM coupling with a suitable partner (e.g., 84) to afford the stilbene derivative $85(96: 4 Z: E)$ in $74 \%$ yield (Scheme 13).

Majchrzak and co-workers [45] demonstrated a synergistic approach involving SM cross coupling and CM to synthesize various substituted trans-stilbene derivatives 89-95 stereoselectively. In this context, 4-vinylphenylboronic acid (86) was subjected to SM coupling using diverse bromoarenes $87 \mathbf{a}-\mathbf{g}$ in the presence of $\left[\mathrm{Pd}\left(\eta^{2}-\mathrm{dba}\right)\left\{\mathrm{P}(o \text {-tolyl })_{3}\right\}_{2}\right]$ catalyst to obtain the cross-coupling products 88a-g (81-96\%). Finally, exposure of olefins 88a-g to G-II catalyst $\mathbf{2}$ in $\mathrm{CH}_{2} \mathrm{Cl}_{2}$ led to the formation of the respective trans-stilbene derivatives 89-95 in high yields
(Scheme 14). It is worth mentioning that the loading of only $0.0001 \mathrm{~mol} \%$ catalyst can effect a CM in an efficient manner.

\section{Biaryl derivatives}

In view of the interesting properties of biaryl derivatives, we have identified a three-step sequence, which involve crossenyne metathesis (CEM), DA reaction followed by SM coupling [46]. To this end, acetylene derivatives 96a,b were subjected to CEM with G-I catalyst 1 under ethylene, which resulted in the formation of the dienes $97 \mathbf{a}(63 \%)$ and $\mathbf{9 7 b}$ (83\%, Scheme 15). Further, treatment of dienes $\mathbf{9 7 a}, \mathbf{b}$ with dimethyl acetylenedicarboxylate (DMAD, 98) separately delivered the corresponding cycloadducts. Subsequently, aromatization was achieved by using DDQ to give biaryl products 99a,b.

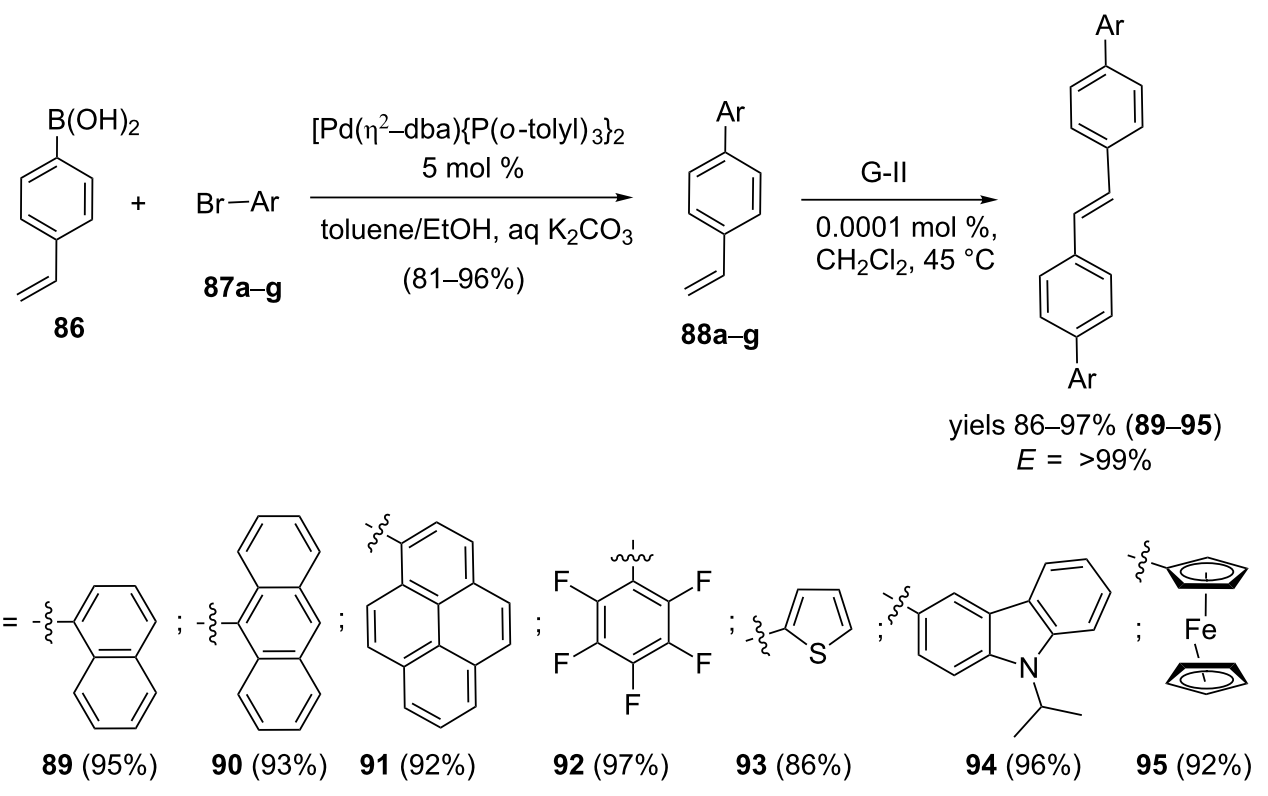

Scheme 14: Synthesis of substituted trans-stilbene derivatives via SM coupling and RCM.

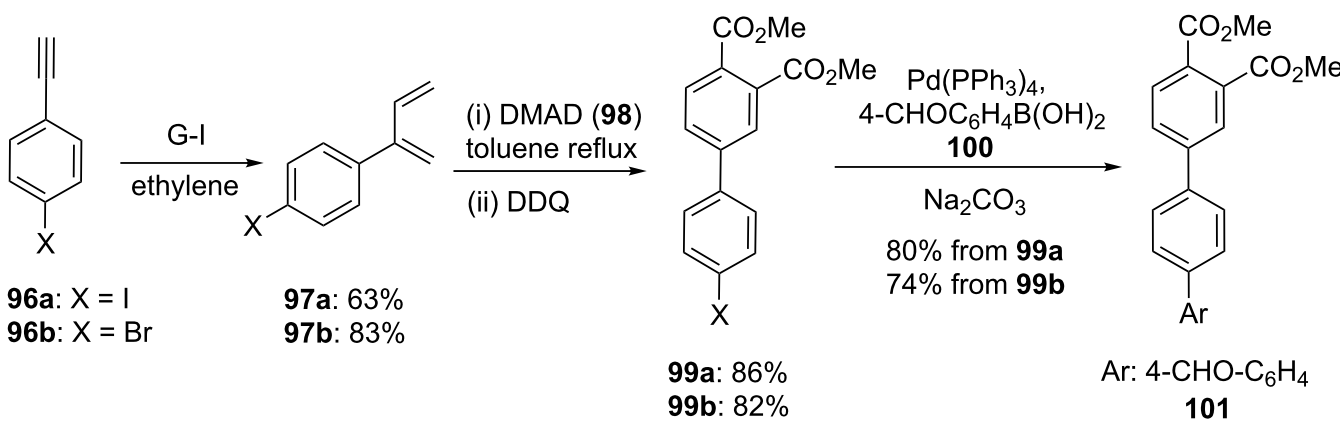


Further, aryl halides 99a,b were subjected to SM coupling by employing various boronic acids (e.g., 4-formylphenylboronic acid (100) to produce biaryl derivative 101 (80\% from 99a and $74 \%$ from $99 b$ ).

Very recently, Suresh Babu and co-workers [47] demonstrated a new route to construct the dibenzocyclooctadiene lignan core of the natural product schisandrene via SM coupling and RCM as key steps. In this context, the SM reaction of boronic acid $\mathbf{1 0 2}$ with bromoaldehyde 103 in the presence of $\operatorname{Pd}_{2}(\mathrm{dba})_{3}$ and the S-Phos ligand provided the cross-coupling product 104 (82\%). Later, it was transformed into the allyl substrate $\mathbf{1 0 5}$ by following a three-step sequence. Afterwards, the aldehyde $\mathbf{1 0 5}$ was treated with vinylmagnesium bromide (106) to furnish diallyl derivative 107 (85\%). Next, diolefinic substrate 107 was exposed to G-II catalyst 2 to furnish the ring-closure product 108 (89\%). Then, $\mathrm{MnO}_{2}$ oxidation of compound 108 offered the keto derivative in $90 \%$ yield. Corey-Bakshi-Shibata (CBS) reduction of the resulting keto derivative produced the hydroxy compound 109 (85\%, ee 98\%). Eventually, hydroxy olefin 109 was subjected to Sharpless asymmetric epoxidation to generate the corresponding epoxide 110. Unfortunately, generation of epoxide was not realized (Scheme 16).

\section{Macrocycles}

To develop new synthetic strategies to various cyclophanes, we conceived a sequential usage of the SM coupling and RCM as key steps [48,49]. In this context, the required dialdehyde 113 (80\%) was prepared via a SM coupling of the dibromo compound 112 with 4-formylphenylboronic acid (100). Treatment of dialdehyde $\mathbf{1 1 3}$ with allyl bromide (28) in the presence of indium powder furnished the RCM precursor 114. Under the influence of the G-II catalyst 2 RCM of diolefinic compound 114 was realized. Then, the cyclized product was subjected to the oxidation sequence with pyridinium chlorochromate (PCC) to generate cylophane derivative $\mathbf{1 1 5}$ in $75 \%$ yield (Scheme 17).

Similarly, treatment of dialdehyde $\mathbf{1 1 3}$ with a freshly prepared Grignard reagent derived from 4-bromobut-1-ene (116) afforded dialkenyl substrate $\mathbf{1 1 7}$, which was subjected to RCM with the aid of G-II catalyst $\mathbf{2}$ to produce a mixture of products

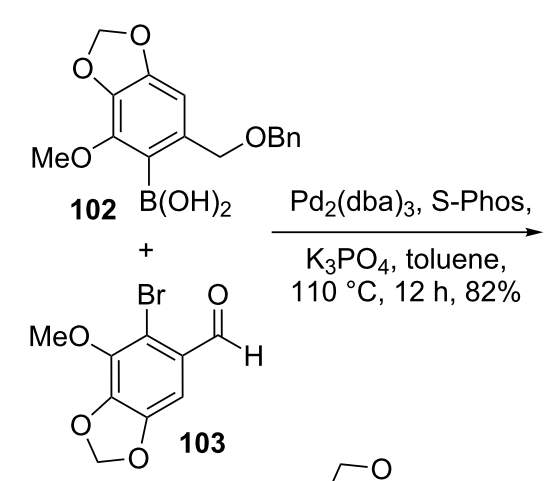<smiles>C=CCc1cc2c(c(OC)c1-c1c(C(O)(C=C)CC)cc3c(c1OC)OCO3)OCO2</smiles><smiles>COc1c2c(cc3c1-c1c(cc4c(c1OC)OCO4)C(O)/C=C/CC3)OCO2</smiles>

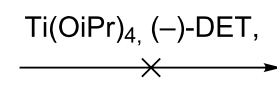

$t$ - BuOOH, $\mathrm{CH}_{2} \mathrm{Cl}_{2}$, $-20{ }^{\circ} \mathrm{C}, 12 \mathrm{~h}$<smiles>COc1c2c(cc(C=O)c1-c1c(COCc3ccccc3)cc3c(c1OC)OCO3)OCO2</smiles>

(i) $\mathrm{Pd} / \mathrm{C}(5 \mathrm{~mol} \%)$, EtOAc, rt, 4 h $80 \%$ (ii) $\mathrm{CBr}_{4}, \mathrm{Ph}_{3} \mathrm{P}, \mathrm{CH}_{2} \mathrm{Cl}_{2}$, $-15{ }^{\circ} \mathrm{C}$ to rt, $4 \mathrm{~h}, 80 \%$

(iii) $\mathrm{CH}_{2}=\mathrm{CHSn}\left[\mathrm{CH}_{3}\left(\mathrm{CH}_{2}\right)_{3}\right]_{3}$, $\mathrm{Pd}_{2}(\mathrm{dba})_{3}$, TFP, NMP, toluene, $80^{\circ} \mathrm{C}, 8 \mathrm{~h}, 78 \%$<smiles>C=CCc1cc2c(c(OC)c1-c1c(C=O)cc3c(c1OC)OCO3)OCO2</smiles>

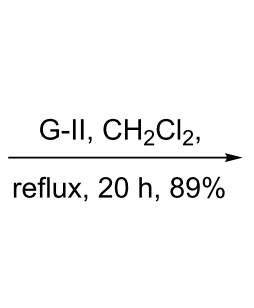<smiles>COc1c2c(cc3c1-c1c(cc4c(c1OC)OCO4)[C@@H](O)C=CC3)OCO2</smiles>

(i) $\mathrm{MnO}_{2}, \mathrm{CH}_{2} \mathrm{Cl}_{2}, 4 \mathrm{~h}, 90 \%$

(ii) (s)-CBS, $\mathrm{BH}_{3} \cdot \mathrm{DMS}$, dry THF, $-78{ }^{\circ} \mathrm{C}$ to rt, $2 \mathrm{~h}, 85 \%$

108
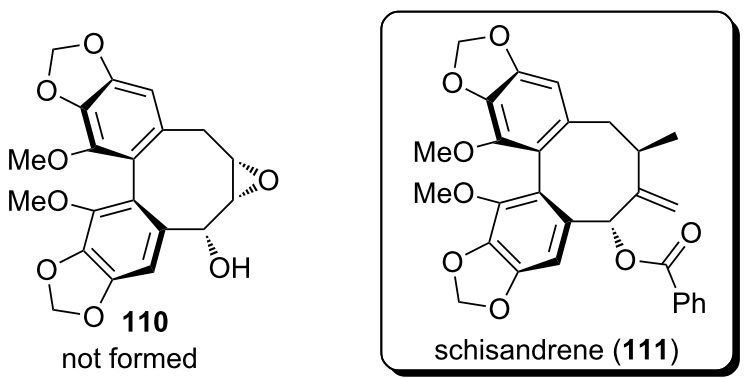


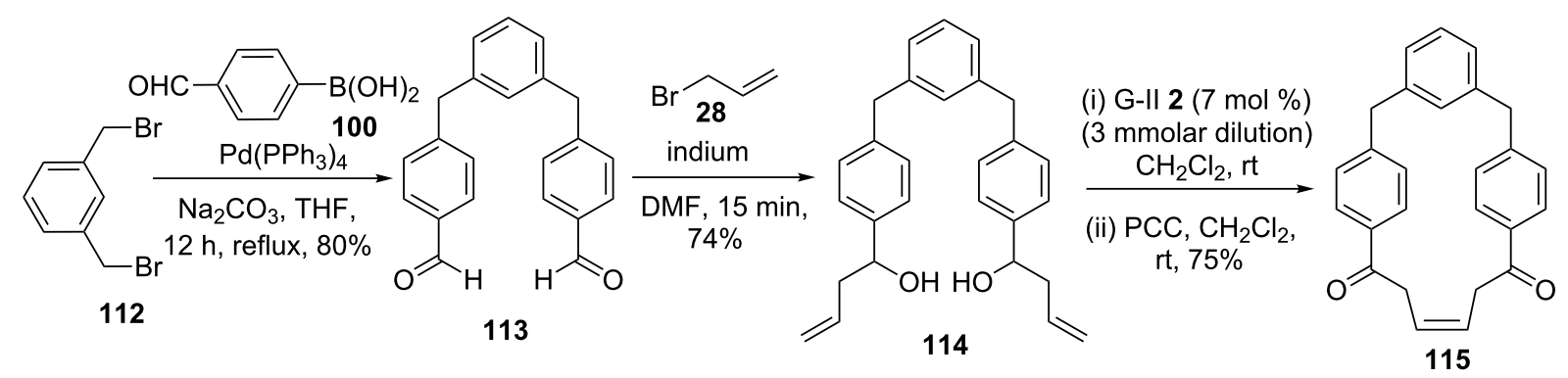

Scheme 17: Synthesis of cyclophane 115 via SM coupling and RCM as key steps.

119 and $\mathbf{1 2 1}$ in combined $47 \%$ yield. It should be noted that the resulting product $\mathbf{1 2 1}$ was obtained through isomerization of the terminal double bond followed by RCM. Later, oxidation of diols 119 and $\mathbf{1 2 1}$ was accomplished with PCC to provide the corresponding diones 120 (79\%) and $\mathbf{1 2 2}$ (76\%) with trans geometry. The stereochemistry was confirmed on the basis of the coupling constant $\left(J=15.0 \mathrm{~Hz},{ }^{1} \mathrm{H}\right.$ NMR spectrum) of the olefinic protons (Scheme 18).

A variety of macrocycles were synthesized through SM cross coupling followed by RCM as key steps [50]. To this end, dibromo compound $\mathbf{1 2 3}$ was subjected to diallylation by using allylboronate ester 12 to form the diallyl derivative 124 (73\%). Treatment of compound $\mathbf{1 2 4}$ with G-I catalyst 1 gave unsaturated dimer 126 (30\%) and monomer 125 (15\%). Subsequently, hydrogenation of compounds $\mathbf{1 2 6}$ and $\mathbf{1 2 5}$ was accomplished with $\mathrm{H}_{2}$ under $\mathrm{Pd} / \mathrm{C}$ catalysis conditions to afford the respective saturated macrocyclic products $127(80 \%)$ and 128 (90\%). Since the small ring cyclophane is highly strained, compound 125 was formed as a minor product (Scheme 19).

Recently, Li et al. [51] disclosed an elegant synthesis of MK-6325 (141) through a sequential usage of RCM and SM coupling as key steps. In this respect, the required RCM precursor 130 was derived from 129 by employing a six-step synthesis sequence. Next, the alkene derivative $\mathbf{1 3 0}$ was subjected to RCM under the influence of Zhan-1B catalyst 4 to deliver the cyclized product 131 (91\%). Later, TFA-mediated deprotection of cyclized product 131 gave amine 132 (97\%). Treatment of chloro derivative 132 with boronate ester 133 provided the SM

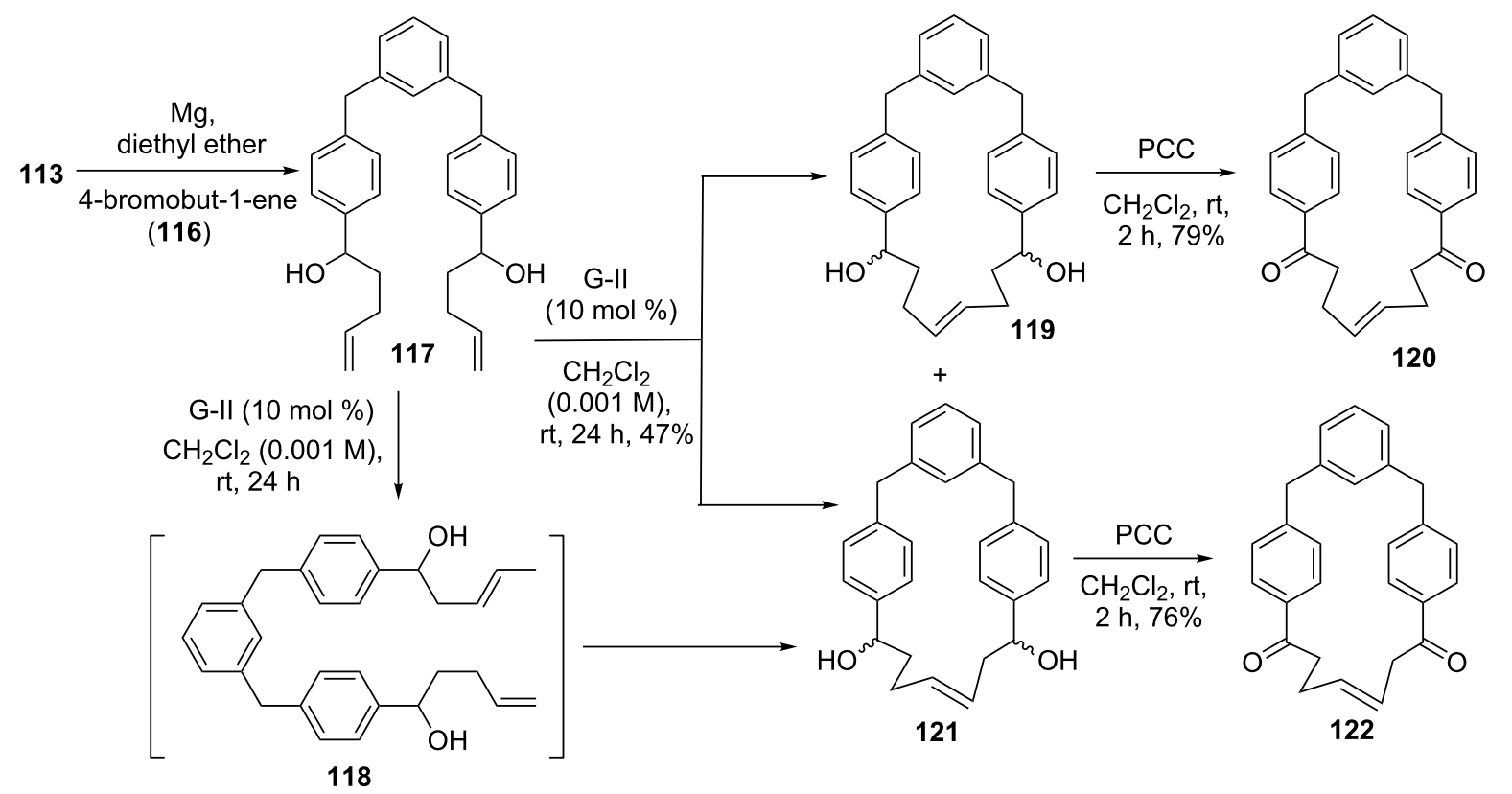


<smiles>CCOCC(Cc1cccc(Br)c1)(Cc1cccc(Br)c1)C(=O)OCC</smiles>

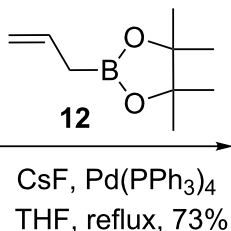

123
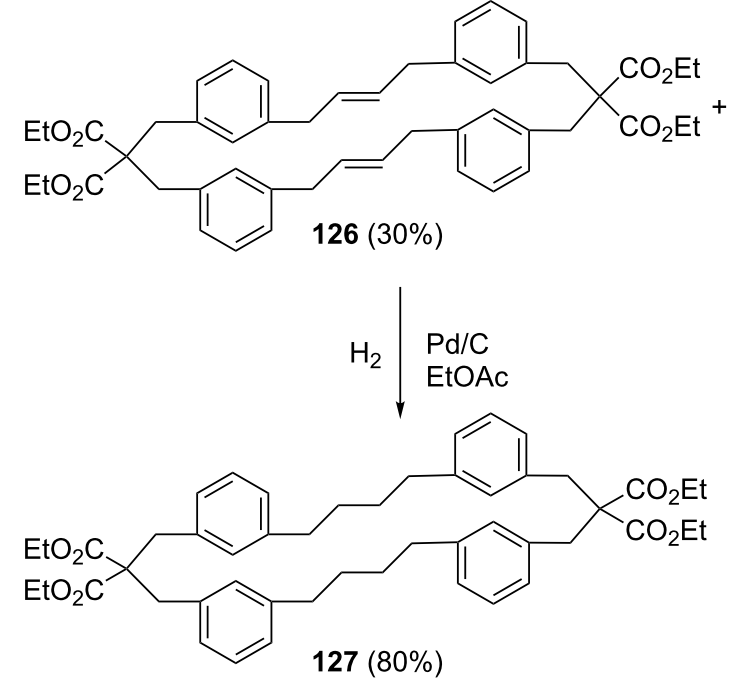

$125(15 \%)$<smiles>CCOC(=O)CC(Cc1cccc(C/C=C\Cc2cccc(CC(C)(C)C)c2)c1)(C(C)=O)C(=O)OCC</smiles>

$\mathrm{H}_{2} \downarrow \begin{aligned} & \mathrm{Pd} / \mathrm{C} \\ & \mathrm{EtOAc}\end{aligned}$<smiles>C=CCc1cccc(CC(Cc2cccc(CC=C)c2)(C(=O)OCC)C(=O)OCC)c1</smiles>

G-I $\mid \begin{aligned} & \mathrm{Ti}(\mathrm{iOPr})_{4} \\ & \mathrm{CH}_{2} \mathrm{Cl}_{2}, 40^{\circ} \mathrm{C}\end{aligned}$<smiles>CCOCC(CC1=CC=CC2=CC=CC(=C1)C2)(Cc1ccccc1)OCC</smiles>

Scheme 19: Synthesis of cyclophanes via SM and RCM.

coupling precursor 134 (77\%). Later, an intramolecular SM coupling of Bpin derivative $\mathbf{1 3 4}$ was realized in the presence of a $\mathrm{Pd}(\mathrm{OAc})_{2}$ catalyst with the aid of the ligand cataCXium A (135) to generate the macrocyclic product 136. Eventually, synthesis of MK-6325 (141) was achieved by adopting saponification followed by amidation (Scheme 20).

\section{Conclusion}

In this review, we have summarized various approaches to a wide range of carbocycles and heterocycles that deals with a strategic utilization of SM coupling and metathesis as key steps. Interestingly, application of these two powerful methods in combination for a $\mathrm{C}-\mathrm{C}$ bond formation process shorten the synthesis sequence for the assembly of the target molecules and thus enhances the ease of preparation of various functional molecules. These processes are considered as "green" because of atom economy and synthetic brevity [52] involved in these reactions $[12,53,54]$. Additionally, several methods are available to remove palladium and ruthenium impurities in minor amounts from the reaction mixture. This aspect is also important in the pharmaceutical industry $[4,55]$.

\section{Biography of the Authors}

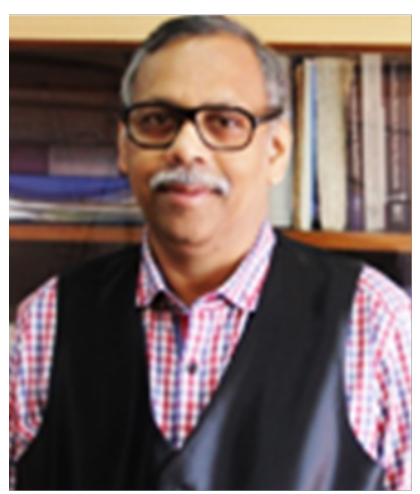

Sambasivarao Kotha graduated with M.Sc. degree in Chemistry from the University of Hyderabad and obtained his Ph.D. in Organic Chemistry from the University of Hyderabad in 1985. Later, he moved to UMIST Manchester, UK and the University of Wisconsin, USA as a research associate. Subsequently, he was appointed as a visiting scientist at Cornell University and as a research chemist at Hoechst Celanese Texas prior to joining IIT Bombay in 1994 as an assistant professor. 


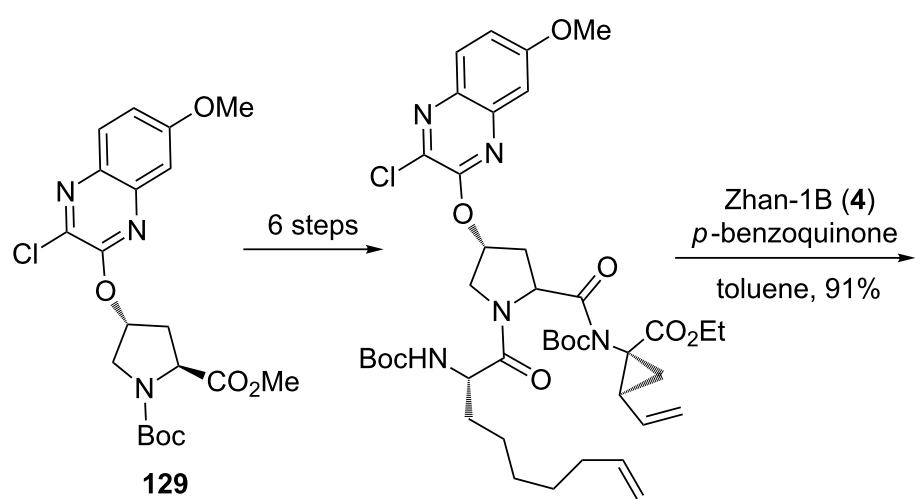

130

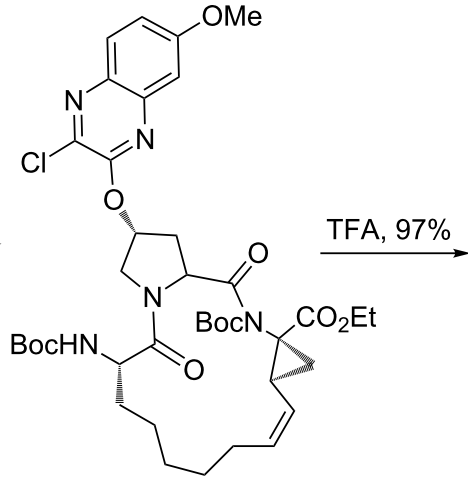

131<smiles>CCOC1(NC(=O)C2CC(Oc3nc4cc(OC)ccc4nc3Cl)CN2C(=O)C(N)CCCCC/C=C\CC(N)=O)CC12CC2</smiles>

132

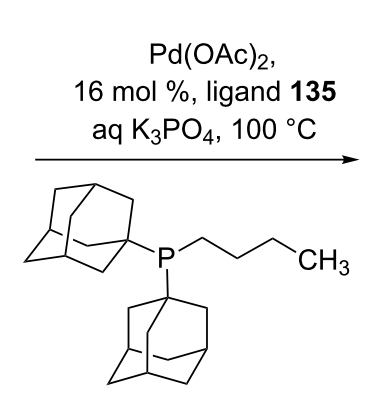

ligand cataCXium A (135)

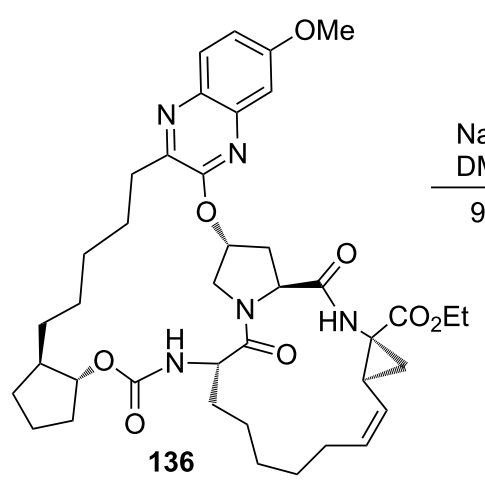

136

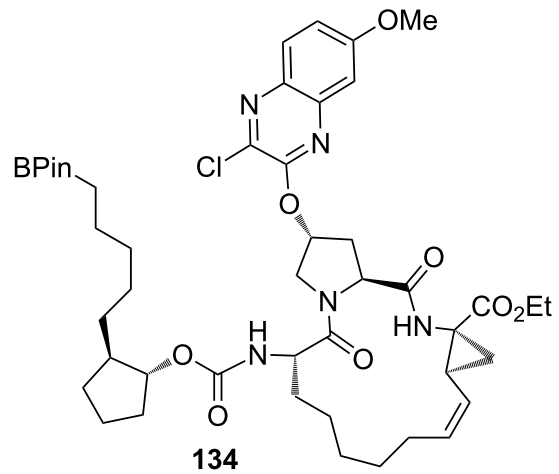

134<smiles>CCCCCCCc1nc2ccc(OC)cc2nc1OC1CC(C(=O)NC2(C(=O)O)CC2)N(C(=O)C(CCCCC/C=C\[NH2+][O-])NC(=O)OC2CCCC2)C1</smiles>

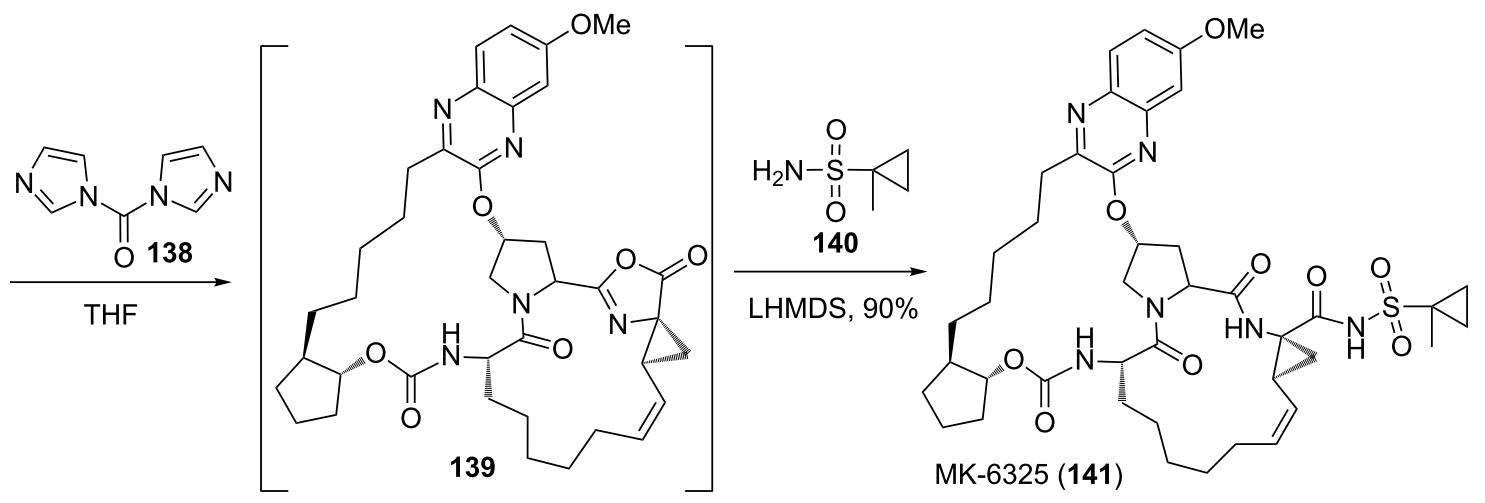


Later, in 2001, he was promoted to Professor. He has published 250 publications in peer-reviewed journals and elected fellow of various academies (FNASc, FASc, FRSC and FNA). He was also associated with editorial advisory boards of several journals. His research interests include: organic synthesis, green chemistry, development of new synthetic methods for unusual amino acids, peptide modifications, cross-coupling reactions, and metathesis. Currently, he occupies the Pramod Chaudhari Chair Professor in Green Chemistry.

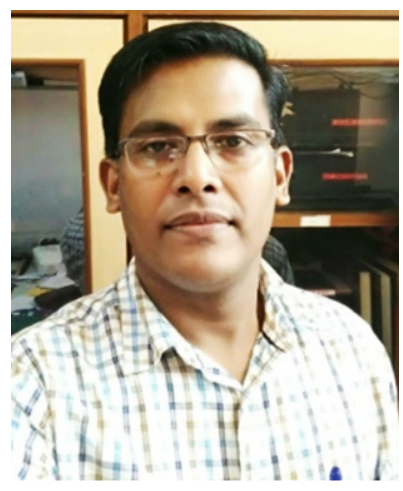

Milind P. Meshram was born in Amravati, Maharashtra, India He obtained his M.Sc. degree in Chemistry from the Amravati University. He joined the Department of Chemistry, IIT Bombay in 2007 and graduated with Ph.D. degree in 2014 (Organic Chemistry) under the supervision of Prof. S. Kotha. Later, he worked with Prof. Dr. Van der Eycken as a PostDoctoral Fellow at the KU Leuven, Belgium under the EMINTE programme. During post-doctoral work his research work was related to organic synthesis under microwave reaction conditions. Presently, he is Research Associate with Prof. S. Kotha. His research interests include various transitionmetal-catalyzed reactions and their applications in organic synthesis.

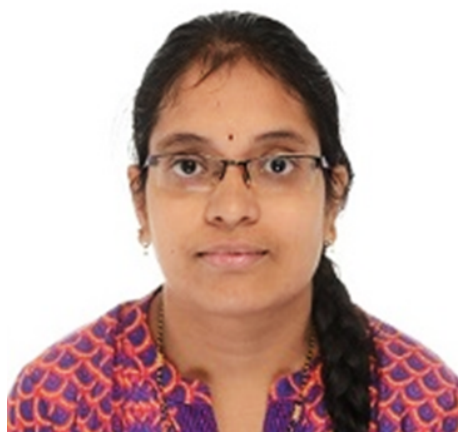

Chandravathi Chakkapalli obtained her B.Sc. and M.Sc. in Chemistry from Andhra University, Andhra Pradesh, India. She completed her Ph.D. under the supervision of Dr. J. S. Yadav from IICT, Hyderabad in 2016. Her research interests are in the area of organic synthesis and green chemistry.

\section{Acknowledgements}

We thank the Council of Scientific and Industrial Research (CSIR), New Delhi [02(0272)/16/EMR-II] for the financial support. SK thanks the Department of Science and Technology (DST), New Delhi for the award of a J. C. Bose fellowship (SR/S2/JCB-33/2010), and Praj Industries, Pune for the Pramod Chaudhari Chair Professorship (Green Chemistry).

\section{ORCID ${ }^{\circledR}$ iDs}

Milind Meshram - https://orcid.org/0000-0002-8922-4363

\section{References}

1. Grubbs, R. H.; Wenzel, A. G.; O'Leary, D. J.; Khosravi, E. Handbook of Metathesis; Wiley-VCH: Weinheim, Germany, 2015; Vol. 1. doi:10.1002/9783527674107

2. Ogba, O. M.; Warner, N. C.; O'Leary, D. J.; Grubbs, R. H. Chem. Soc. Rev. 2018, 47, 4510-4544. doi:10.1039/c8cs00027a

3. Kotha, S.; Lahiri, K. Synlett 2007, 2767-2784. doi:10.1055/s-2007-990954

4. Kotha, S.; Dipak, M. K. Tetrahedron 2012, 68, 397-421. doi:10.1016/j.tet.2011.10.018

5. Kotha, S.; Sreenivasachary, N. Indian J. Chem. 2001, 40B, 763-780.

6. Kotha, S.; Misra, S.; Sreevani, G.; Babu, B. Curr. Org. Chem. 2013, 17, 2776-2795. doi:10.2174/13852728113179990118

7. Carey, F. A.; Sunburg, R. J. Reactions Involving Transition Metals. Advanced Organic Chemistry: Reaction and Synthesis, 5th ed.; Springer: New York, NY, U.S.A., 2007. doi:10.1007/978-0-387-71481-3

8. Suzuki, A.; Miyaura, N.; Yamada, K. Tetrahedron Lett. 1979, 20 , 3437-3440. doi:10.1016/s0040-4039(01)95429-2

9. Miyaura, N.; Suzuki, A. J. Chem. Soc., Chem. Commun. 1979, 866-867. doi:10.1039/c39790000866

10. Miyaura, N.; Suzuki, A. Chem. Rev. 1995, 95, 2457-2483. doi:10.1021/cr00039a007

11. Kotha, S.; Lahiri, K.; Kashinath, D. Tetrahedron 2002, 58, 9633-9695. doi:10.1016/s0040-4020(02)01188-2

12. Chatterjee, A.; Ward, T. R. Catal. Lett. 2016, 146, 820-840. doi:10.1007/s10562-016-1707-8

13. Lennox, A. J. J.; Lloyd-Jones, G. C. Chem. Soc. Rev. 2014, 43, 412-443. doi:10.1039/c3cs60197h

14. Molander, G. A. J. Org. Chem. 2015, 80, 7837-7848. doi:10.1021/acs.joc.5b00981

15. Hall, D. G., Ed. Boronic Acids, 2nd ed.; Wiley-VCH Verlag GmbH: Weinheim, Germany, 2011. doi:10.1002/9783527639328

16. Hemelaere, R.; Carreaux, F.; Carboni, B. J. Org. Chem. 2013, 78, 6786-6792. doi:10.1021/jo400872x

17. Topolovčan, N.; Panov, I.; Kotora, M. Org. Lett. 2016, 18, 3634-3637. doi:10.1021/acs.orglett.6b01682

18. Kotha, S.; Mandal, K. Chem. - Asian J. 2009, 4, 354-362. doi:10.1002/asia.200800244

19. Moulin, E.; Nevado, C.; Gagnepain, J.; Kelter, G.; Fiebig, H.-H.; Fürstner, A. Tetrahedron 2010, 66, 6421-6428. doi:10.1016/j.tet.2010.05.043

20. Liao, L.; Zhou, J.; Xu, Z.; Ye, T. Angew. Chem., Int. Ed. 2016, 55, 13263-13266. doi:10.1002/anie.201606679 
21. Reck, L. M.; Haberhauer, G.; Lüning, U. Eur. J. Org. Chem. 2016, 1119-1131. doi:10.1002/ejoc.201501289

22. Sakamoto, K.; Hakamata, A.; Tsuda, M.; Fuwa, H. Angew. Chem., Int. Ed. 2018, 57, 3801-3805. doi:10.1002/anie.201800507

23. Inoue, M.; Komori, T.; Iwanaga, T.; Toyota, S. Chem. Lett. 2017, 46, 1836-1838. doi:10.1246/cl.170884

24. Kuttner, J. R.; Hilt, G. Macromolecules 2014, 47, 5532-5541. doi:10.1021/ma5012446

25. Sasaki, M.; Ishikawa, M.; Fuwa, H.; Tachibana, K. Tetrahedron 2002, 58, 1889-1911. doi:10.1016/s0040-4020(02)00045-5

26. Essig, S.; Schmalzbauer, B.; Bretzke, S.; Scherer, O.; Koeberle, A.; Werz, O.; Müller, R.; Menche, D. J. Org. Chem. 2016, 81, 1333-1357. doi:10.1021/acs.joc.5b02844

27. Arican, D.; Braukmüller, S.; Brückner, R. Chem. - Eur. J. 2017, 23, 4537-4541. doi:10.1002/chem.201700622

28. Maitra, S.; Bodugam, M.; Javed, S.; Hanson, P. R. Org. Lett. 2016, 18, 3094-3097. doi:10.1021/acs.orglett.6b01248

29. Kotha, S.; Panguluri, N. R.; Ali, R. Eur. J. Org. Chem. 2017, 5316-5342. doi:10.1002/ejoc.201700439

30. Jana, A.; Misztal, K.; Żak, A.; Grela, K. J. Org. Chem. 2017, 82, 4226-4234. doi:10.1021/acs.joc.7b00200

31. Kotha, S.; Shah, V. R.; Mandal, K. Adv. Synth. Catal. 2007, 349, 1159-1172. doi:10.1002/adsc.200600469

32. Kotha, S.; Behera, M.; Shah, V. R. Synlett 2005, 1877-1880. doi:10.1055/s-2005-871569

33. Johnson, M. M.; Ngwira, K. J.; Rousseau, A. L.; Lemmerer, A.; de Koning, C. B. Tetrahedron 2018, 74, 12-18. doi:10.1016/j.tet.2017.11.023

34. Kotha, S.; Ali, R.; Srinivas, V.; Krishna, N. G. Tetrahedron 2015, 71 , 129-138. doi:10.1016/j.tet.2014.11.024

35. Kotha, S.; Mandal, K. Tetrahedron Lett. 2004, 45, 1391-1394. doi:10.1016/j.tetlet.2003.12.075

36. Kotha, S.; Ali, R. Turk. J. Chem. 2015, 39, 1190-1198. doi:10.3906/kim-1502-116

37. Ali, R. Diversity oriented approach to spirocycles and heterocycles via olefin metathesis, cyloaddition reaction, Fischer indolization, and Suzuki-Miyaura cross-coupling reaction as key steps. Ph.D. Thesis, IIT, Bombay, India, 2015.

38. Lebrun, S.; Couture, A.; Deniau, E.; Grandclaudon, P. Tetrahedron Lett. 2011, 52, 1481-1484. doi:10.1016/j.tetlet.2011.01.113

39. Schmidt, B.; Krehl, S.; Kelling, A.; Schilde, U. J. Org. Chem. 2012, 77, 2360-2367. doi:10.1021/jo2026564

40. Barthelemy, A.-L.; Prieto, A.; Diter, P.; Hannedouche, J.; Toffano, M.; Anselmi, E.; Magnier, E. Eur. J. Org. Chem. 2018, 3764-3770. doi:10.1002/ejoc.201800324

41. Kotha, S.; Shah, V. R. Eur. J. Org. Chem. 2008, 1054-1064. doi:10.1002/ejoc.200700921

42. Kotha, S.; Mandal, K.; Tiwari, A.; Mobin, S. M. Chem. - Eur. J. 2006, 12, 8024-8038. doi:10.1002/chem.200600540

43. Kotha, S.; Srinivas, V.; Krishna, N. G. Heterocycles 2012, 86, 1555-1563. doi:10.3987/com-12-s(n)89

44. Kiesewetter, E. T.; O’Brien, R. V.; Yu, E. C.; Meek, S. J.; Schrock, R. R.; Hoveyda, A. H. J. Am. Chem. Soc. 2013, 135, 6026-6029. doi:10.1021/ja403188t

45. Majchrzak, M.; Wilkowski, G.; Kubicki, M. Eur. J. Org. Chem. 2017, 4291-4299. doi:10.1002/ejoc.201700602

46. Kotha, S.; Seema, V. Synlett 2011, 2329-2334. doi:10.1055/s-0030-1260315
47. Venkanna, A.; Poornima, B.; Siva, B.; Babu, B. H.; Babu, K. S. Synlett 2018, 29, 908-911. doi:10.1055/s-0036-1591539

48. Kotha, S.; Mandal, K.; Arora, K. K.; Pedireddi, V. R. Adv. Synth. Catal. 2005, 347, 1215-1218. doi:10.1002/adsc.200404373

49. Kotha, S.; Mandal, K. Eur. J. Org. Chem. 2006, 5387-5393. doi:10.1002/ejoc.200600549

50. Kotha, S.; Chavan, A. S.; Shaikh, M. J. Org. Chem. 2012, 77, 482-489. doi:10.1021/jo2020714

51. Li, H.; Scott, J. P.; Chen, C.-y.; Journet, M.; Belyk, K.; Balsells, J.; Kosjek, B.; Baxter, C. A.; Stewart, G. W.; Wise, C.; Alam, M.; Song, Z. J.; Tan, L. Org. Lett. 2015, 17, 1533-1536. doi:10.1021/acs.orglett.5b00418

52. Hudlicky, T.; Reed, J. W. The Way of Synthesis; Wiley-VCH: Weinheim, Germany, 2007; p 98.

53. Hughes, D.; Wheeler, P.; Ene, D. Org. Process Res. Dev. 2017, 21 , 1938-1962. doi:10.1021/acs.oprd.7b00319

54. Náray-Szabó, G.; Mika, L. T. Green Chem. 2018, 20, 2171-2191. doi:10.1039/c8gc00514a

55. Szczepaniak, G.; Ruszczyńska, A.; Kosiński, K.; Bulska, E.; Grela, K. Green Chem. 2018, 20, 1280-1289. doi:10.1039/c7gc03324a

\section{License and Terms}

This is an Open Access article under the terms of the Creative Commons Attribution License (http://creativecommons.org/licenses/by/4.0). Please note that the reuse, redistribution and reproduction in particular requires that the authors and source are credited.

The license is subject to the Beilstein Journal of Organic Chemistry terms and conditions: (https://www.beilstein-journals.org/bjoc)

The definitive version of this article is the electronic one which can be found at: doi:10.3762/bjoc. 14.223 